\title{
Health risks and benefits from calcium and vitamin D supplementation: Women's Health Initiative clinical trial and cohort study
}

\author{
R. L. Prentice • M. B. Pettinger • R. D. Jackson • J. Wactawski-Wende • A. Z. LaCroix • \\ G. L. Anderson - R. T. Chlebowski - J. E. Manson - L. Van Horn • M. Z. Vitolins • \\ M. Datta • E. S. LeBlanc • J. A. Cauley • J. E. Rossouw
}

Received: 27 July 2012 / Accepted: 31 October 2012 / Published online: 4 December 2012

(C) The Author(s) 2012. This article is published with open access at Springerlink.com

\begin{abstract}
Summary The Women's Health Initiative (WHI) doubleblind, placebo-controlled clinical trial randomly assigned 36,282 postmenopausal women in the U.S. to $1,000 \mathrm{mg}$ elemental calcium carbonate plus $400 \mathrm{IU}$ of vitamin $\mathrm{D}_{3}$ daily or placebo, with average intervention period of 7.0 years. The trial was designed to test whether calcium plus vitamin D supplementation in a population in which the use of these supplements was widespread would reduce hip fracture, and secondarily, total fracture and colorectal cancer.

Introduction This study further examines the health benefits and risks of calcium and vitamin D supplementation using WHI data, with emphasis on fractures, cardiovascular disease, cancer, and total mortality.
\end{abstract}

Electronic supplementary material The online version of this article (doi:10.1007/s00198-012-2224-2) contains supplementary material, which is available to authorized users.

R. L. Prentice · M. B. Pettinger · A. Z. LaCroix · G. L. Anderson Fred Hutchinson Cancer Research Center, Seattle, WA, USA

R. D. Jackson

Ohio State University, Columbus, OH, USA

J. Wactawski-Wende

State University of New York, Buffalo, NY, USA

R. T. Chlebowski

Los Angeles Biomedical Research Institute at Harbor-UCLA

Medical Center, Torrance, CA, USA

J. E. Manson

Brigham and Women's Hospital, Harvard Medical School, Boston, MA, USA

L. Van Horn

Northwestern University, Chicago, IL, USA
Methods WHI calcium and vitamin D randomized clinical trial (CT) data through the end of the intervention period were further analyzed with emphasis on treatment effects in relation to duration of supplementation, and these data were contrasted and combined with corresponding data from the WHI prospective observational study (OS).

Results Among women not taking personal calcium or vitamin D supplements at baseline, the hazard ratio [HR] for hip fracture occurrence in the CT following 5 or more years of calcium and vitamin D supplementation versus placebo was 0.62 (95\% confidence interval (CI), 0.38-1.00). In combined analyses of $\mathrm{CT}$ and OS data, the corresponding HR was 0.65 (95\% CI, 0.44-0.98). Supplementation effects were not apparent on the risks of myocardial infarction,

M. Z. Vitolins $\cdot$ M. Datta

Wake Forest University Health Sciences, Winston-Salem, NC, USA

E. S. LeBlanc

Kaiser Permanente Center for Health Research, Portland, OR, USA

J. A. Cauley

Graduate School of Public Health, University of Pittsburgh,

Pittsburgh, PA, USA

J. E. Rossouw

National Heart, Lung and Blood Institute, National Institutes of Health, Bethesda, MD, USA

\section{R. L. Prentice $(\bowtie)$}

Public Health Sciences Division, Fred Hutchinson Cancer Research Center, 1100 Fairview Avenue North, M3-A410, POB 19024, Seattle, WA 98109-1024, USA

e-mail: rprentic@whi.org 
coronary heart disease, total heart disease, stroke, overall cardiovascular disease, colorectal cancer, or total mortality, while evidence for a reduction in breast cancer risk and total invasive cancer risk among calcium plus vitamin D users was only suggestive.

Conclusion Though based primarily on a subset analysis, long-term use of calcium and vitamin D appears to confer a reduction that may be substantial in the risk of hip fracture among postmenopausal women. Other health benefits and risks of supplementation at doses considered, including an elevation in urinary tract stone formation, appear to be modest and approximately balanced.

Keywords Calcium - Cancer - Cardiovascular disease . Fractures $\cdot$ Health risks and benefits $\cdot$ Vitamin D

\section{Introduction}

The Women's Health Initiative (WHI) double-blind, placebocontrolled clinical trial (CT) randomly assigned 36,282 postmenopausal women in the U.S. to $1,000 \mathrm{mg}$ elemental calcium carbonate plus 400 IU of vitamin $\mathrm{D}_{3}$ daily or placebo, with average intervention period of 7.0 years. The trial was designed to test whether calcium plus vitamin $\mathrm{D}(\mathrm{CaD})$ supplementation in a population in which the use of these supplements was widespread would reduce hip fracture, and secondarily, total fracture and colorectal cancer. Even though $\mathrm{CaD}$ led to a significantly higher hip and total body bone mineral density than placebo $(P<0.01)$, there was no compelling evidence for hip or total fracture risk reduction [1]. Among women who adhered to study medications, however, there was a lower hip fracture incidence in the intervention group [1], though this type of adherence-adjusted analysis involves additional modeling assumptions and lacks the reliability of the corresponding intention-to-treat analysis. Additional analyses led to reports of no clear evidence of benefit or harm for colorectal cancer [2], breast cancer [3], or other invasive cancer [4], though the possibility of a breast cancer risk reduction among women using little or no personal calcium supplements was noted [3]. Additional reports noted no clear evidence of influence on coronary heart disease (CHD) risk, defined in WHI and here as nonfatal myocardial infarction (MI) or CHD death [5], and to the possibility of a reduction in total mortality [6]. A modest elevation in urinary tract stone occurrence in the intervention group was also observed $[1,7]$.

The WHI trial has been criticized in that participating women were allowed to continue their personal use of calcium and/or vitamin D, in addition to taking study pills [8]. Our perspective, as WHI investigators, is that the question of health risks and benefits associated with $\mathrm{CaD}$ supplementation, beyond the use of personal supplements, is of direct importance to postmenopausal women in the general population. We agree, however, that subset analyses restricted to women not taking personal supplements are of considerable interest from both etiologic and public health perspectives.

Bolland et al. [8] reanalyzed WHI CaD trial data and reported an interaction $(P=0.04)$ in hazard ratio (HR) for "clinical MI" according to whether or not women were not using personal calcium supplements at baseline. A similar interaction was reported for combined clinical MI and stroke. These authors summarize that WHI trial data do not provide "definitive evidence" of an adverse effect of calcium and vitamin D on cardiovascular events, but they argue that data from other trials of calcium and vitamin $\mathrm{D}$, or of calcium alone, in conjunction with WHI data, lead to the conclusion that calcium supplements with or without vitamin D increase the risk of cardiovascular events.

Essentially the same investigator group reanalyzed the WHI trial data further and reported [9] an HR interaction for total cancer and invasive breast cancer, but not for hip or total fractures or total mortality, this time according to whether participating women were using personal supplements of either calcium or vitamin D at baseline. They interpreted these data as providing evidence of benefit for breast cancer and total cancer among women not taking personal supplements. Chlebowski et al. [10] pointed out the need for a cautious interpretation in these subgroup analyses and described lack of support for a breast cancer risk reduction from other WHI data sources.

Here, we use WHI data resources to examine these topics further, with emphasis on the experience of women in the CT who were not using calcium or vitamin $\mathrm{D}$ supplements at baseline, as well as on the experience of the overall trial cohort. We include comparative analyses from the WHI Observational Study (OS), a prospective cohort study among 93,676 postmenopausal women drawn from the same catchment areas, for independent assessment of calcium and vitamin D health risks and benefits in WHI populations. Since OS women may have used these supplements for some years prior to WHI enrollment, these data have potential to augment trial information on the health effects of longer-term supplementation (e.g., 5 or more years). In fact, there have been several observational study reports of calcium supplementation in relation to cardiovascular disease [11-15]. While most of these report null or non-significant associations, the most recent of these reported a noteworthy increase in MI, but not stroke, incidence among the $3.6 \%$ of an EPIC-Heidelberg cohort enrollees who were identified as calcium supplement users [15].

These types of observational analyses can be difficult to interpret since nutritional supplement users tend to have quite different characteristics from non-users [e.g., 16], typically leaving uncertainty as to how completely confounding has been controlled. Also, common reasons for taking nutritional supplements include the belief that these preparations may prevent chronic diseases, such as cardiovascular 
disease, osteoporosis, and cancer $[16,17]$, raising the specter of "confounding by indication", which may tend to offset any "healthy supplement user" bias. Here, as in our earlier WHI combined CT and OS analyses of postmenopausal hormone therapy [18-23], our analyses allow for outcomespecific residual confounding in the OS. In effect, these combined CT and OS analyses allow an entirely separate overall HR from the OS versus the CT, so that OS data are used very conservatively to strengthen analysis of temporal HR variation patterns. The OS data also permit some examination of disease outcome associations for calcium and vitamin D supplementation separately.

Analyses presented here examine a range of clinical outcomes including fractures, invasive cancers, cardiovascular diseases, and total mortality. In each case, beyond overall supplementation effects, temporal associations of the HR with duration of supplementation, and the agreement of patterns between clinical trial and observational study, are examined. Urinary tract stone occurrence analyses in the CT, by personal supplement use category, are also presented to facilitate health benefit versus risk consideration.

\section{Methods}

Study populations and calcium and vitamin D supplementation

A total of 36,282 postmenopausal women 50-79 years of age were randomized at 40 clinical sites to $1,000 \mathrm{mg}$ calcium plus $400 \mathrm{IU}$ vitamin $\mathrm{D}_{3}$ daily, given in two equal doses, versus placebo in the WHI CaD trial during 1994-99. Concurrent calcium supplementation was permitted, as was vitamin D supplementation up to 600 IU daily (later increased to 1,000 IU daily). Details of the study design [24] and baseline characteristics $[1,2,25]$ have been presented. All participating women provided written informed consent.

No personal use of calcium or vitamin D supplements at baseline was reported by $42.2 \%(15,302)$ of trial enrollees, whereas $43.5 \%(15,796), 9.4 \%(3,419)$, and $2.9 \%(1,060)$ reported use of calcium plus vitamin $\mathrm{D}$, calcium only, and vitamin D only, respectively, while baseline supplementation information was not available for $1.9 \%$ (705) of women. Both single supplement and multivitamin/multimineral supplements were included in assessing personal use.

The companion WHI prospective Observational Study (OS) enrolled 93,676 postmenopausal women 50-79 years of age from the same catchment population during 1994-98. Baseline characteristics have been presented [26]. To align with CT exclusionary criteria, we excluded 5,145 women with a baseline history of breast cancer, 15,511 women with no mammogram within 2 years prior to OS enrollment, 1,108 daily corticosteroid users, and 5,675 women who reported urinary tract stones at baseline, leaving 68,719 OS women. Of these, $34.3 \%(23,561)$ reported no baseline supplementation with calcium or vitamin D, $49.9 \%$ $(34,257)$ reported use of both calcium and vitamin D, $12.5 \%(8,576)$ reported calcium only, and $3.4 \%(2,325)$ reported vitamin D only. Among the 42,833 baseline calcium users, the 5th, 10th, 25th, 50th, 75th, 90th, and 95th percentiles for daily dosage (milligrams per day) were $57,143,200,571,1,000,1,305$, and 1,640, respectively. We defined baseline calcium users in the OS as those taking $\geq 500 \mathrm{mg} /$ day and excluded those consuming a lower dosage from our analysis. This cutpoint gives a user group having average daily dose similar to the $1,000 \mathrm{mg}$ /day used in the WHI trial. Similarly, the corresponding percentiles for vita$\min \mathrm{D}$ (IU/day) were 125, 171, 400, 400, 400, 600, and 800 with $58 \%$ of users reporting $400 \mathrm{IU} /$ day. We defined vitamin D users in the OS as those taking $\geq 400 \mathrm{IU} /$ day and excluded those taking a lower dosage from analysis. Following these exclusions, there were 15,476 calcium plus vitamin D users, 5,941 calcium-only users, and 1,914 vitamin D-only users at baseline in the OS which along with the previously mentioned 23,561 non-users of either supplement entails 46,892 OS women.

Data collection, follow-up, and outcome ascertainment

Clinical outcomes were self-reported semiannually in the CT and annually in the OS [27]. Medical record documentation of these reports was obtained and diagnoses were confirmed at WHI clinical centers by physician adjudicators who were blinded to clinical trial randomization assignments. All clinical outcomes considered here, except certain fractures in the OS, were locally confirmed in this manner. Additionally, cases of coronary heart disease (CHD), stroke, and death were further adjudicated by a central committee in the CT, as were a fraction of such cases in the OS. Also, locally confirmed cases of breast cancer, colorectal cancer, and hip fracture in both the CT and OS were centrally reviewed and classified at the WHI clinical coordinating center. Fractures other than hip fractures were also adjudicated in the CT, as was the case for a small fraction of other fractures in the OS. Otherwise, self-report of fracture was relied on in the OS.

Information on adherence to assigned study pills was obtained semiannually in the CT through unused pill counts. Dietary supplement data were collected in both the CT and OS during in-person clinic visits. Women brought supplement bottles to the baseline clinic visit and to annual visits thereafter in the CT and to the baseline and 3-year clinic visit in the OS. A standardized interviewer-administered four-page form was used to collect information on single vitamin and mineral supplements and on multivitamin/multimineral use. Staff members directly transcribed the ingredients for each 
supplement and asked participants about the frequency (pills/ week) and duration (months and years) of use for each supplement $[28,29]$.

The $\mathrm{CaD}$ trial ended as planned in March 2005 after an average intervention period of 7.0 years. Follow-up data from the OS are included here through 12/16/2004 to provide a comparable average follow-up period of 7.2 years. More recent health risk and benefit follow-up data from the trial are currently being consolidated for a separate presentation.

Standard procedures were used in the CT and OS to collect data on age, race/ethnicity, reproductive/gynecologic history, education, physical activity, medical history, family or personal history of cancer or coronary heart disease, diabetes mellitus, current health status, tobacco and alcohol use, and self-administered food frequency questionnaire. The WHI food frequency questionnaire (FFQ), in English or Spanish, involved 122 foods or food groups, 19 adjustment questions, 4 summary questions, and was designed to assess typical intakes over the preceding 3 months [30]. Medication inventories were obtained at clinic visits, in the same manner as dietary supplements.

\section{Statistical analysis}

Principal data analyses focus on the estimation of hazard ratios corresponding to calcium and vitamin $\mathrm{D}$ supplementation, combined and separately, for each of the following clinical outcomes: hip fracture, total fracture, invasive colorectal cancer, invasive breast cancer, total invasive cancer (excluding non-melanoma skin cancer), total mortality, MI, $\mathrm{CHD}$, total heart disease (CHD, revascularization, angina pectoris, congestive heart failure), stroke (combined ischemic and hemorrhagic), and total cardiovascular disease (CVD) (total heart disease, stroke, carotid artery disease, peripheral vascular disease).

For each clinical outcome, the baseline hazard rate in the Cox regression model is stratified on cohort (CT versus OS), baseline age (5-year categories), and current use of postmenopausal estrogens or estrogens plus progestin defined as randomized to treatment if in the WHI hormone therapy trials [24] and as current hormone therapy use at baseline otherwise. Prior use of estrogens or estrogens plus progestin, duration of any such prior use, and FFQ estimates of usual calcium and vitamin D consumption were also included as a modeled regression variables in the Cox model, in both the CT and the OS. Time from WHI enrollment is the "basic time variable" in these analyses. Hazard ratios were calculated separately for $<2,2-5$, and $\geq 5$ years from initiation of supplementation to assess the temporal relationship between supplementation and any effects on clinical outcome. In the CT, time from supplement initiation is defined as time from randomization, whereas in the OS time from initiation of supplement use is defined as the sum of duration of use at baseline plus time from OS enrollment. Duration of use was defined as the longer of the two durations for women using both calcium and vitamin D supplements at baseline.

To further control confounding in the OS the hazard ratio regression model included an outcome-specific list of potential baseline confounding factors as is shown in Supplementary Table 1. For each outcome, this list included a linear term in age, an indicator of non-white ethnicity, body mass index (BMI) categorized variables for 25-29.9, for 30-34.9, and for $\geq 35.0$ along with a linear term in BMI, and indicator variables for current or past cigarette smoking, in addition to other listed outcome-specific variables.

Analyses for each clinical outcome category were carried out using the entire CT enrollment, and also in the subsets of women who were not taking personal calcium or vitamin D supplements at baseline ("No personal supplements" subset) or were doing so ("Personal supplements" subset), and HR equality between these subsets was tested. For each analysis hazard ratios (HRs) and estimated $95 \%$ confidence intervals (CIs) are presented according to years from supplement initiation $(<2,2-5$, and $>5)$ as a time-varying covariate. Significance levels ( $P$ values) are presented for a test of trend across the three time from initiation categories, coded as 0,1 , or 2 , respectively. In addition, corresponding HR estimates from combined trial and observational data sets are given. These analyses allow for a residual confounding in the OS, by including a product term in the regression model between the OS versus $\mathrm{CT}$ indicator variable and the $\mathrm{CaD}$ user indicator variable. This variable allows the HR for $\mathrm{CaD}$ supplementation to differ by an overall multiplicative factor in the OS compared to the $\mathrm{CaD}$ trial, so that the $\mathrm{OS}$ data contribute to HR patterns with time from initiation but not to the absolute HR assessments in these combined analyses. With this modeling approach, overall HRs from combined CT and OS analyses are identical to those from the $\mathrm{CT}$ alone; but HR trend tests, which combine contributions from each cohort, may be strengthened by inclusion of the OS data. HRs and $95 \%$ CIs for the entire follow-up period were calculated also, separately for the CT and OS.

Additional HR analyses in the CT censor the follow-up for women 6 months after a change from baseline in supplementation category, allowing the HRs to be interpreted in terms of duration of supplement use among adherent women, with continuing adherence defined as taking $80 \%$ or more of assigned study medications in the preceding year. These adherence-adjusted analyses were conducted with and without inverse probability weighting in the Cox model, with weighting by estimated adherence probability, and with adherence probabilities estimated in a time-varying fashion using logistic regression models that include the Supplementary Table 1 variables. 
Analyses were also conducted separately according to decade of baseline age and according to prior history of CVD.

Nominal $95 \%$ CIs are presented for HR parameters, and all $P$ values presented are 2 -sided.

\section{Results}

Table 1 shows number of cases for each clinical outcome and age-adjusted incidence rates for both cohorts according to randomization assignment in the $\mathrm{CT}$ and according to baseline use of calcium and vitamin D supplements in the OS. Incidence rates for most outcomes differed little between randomized groups in the CT.

Table 2 provides HR estimates for fracture, and death according to years from $\mathrm{CaD}$ initiation, both for the $\mathrm{CT}$ as a whole and for the trial subset not using personal calcium or vitamin $\mathrm{D}$ at baseline; for the OS with outcome-specific confounding control; and for the combined CT and OS, with CT component including either the entire trial cohort or the subset not using personal supplements.

In women not taking supplements at baseline, the HR for hip fracture in the $\mathrm{CT}$ following 5 or more years of $\mathrm{CaD}$ supplementation versus placebo was 0.62 (95\% CI, 0.38 to 1.00). In combined analyses of $\mathrm{CT}$ and $\mathrm{OS}$ data (with residual confounding provision in the OS), the corresponding HR was 0.65 (95\% CI, 0.44 to 0.98$)$ with evidence $(P=0.02)$ of HR trend with time from calcium and vitamin $\mathrm{D}$ initiation. Thus, there was evidence for lower hip fracture rates following some years of calcium plus vitamin D use in the subset of women not taking personal calcium or vitamin D supplements. This risk reduction was suggestive, but not clearly evident in the trial cohort as a whole (HR 0.82; $95 \% \mathrm{CI}, 0.61$ to 1.12 ), or in combined trial and OS analyses. These combined overall CT and OS analyses provide some evidence for hip fracture benefit in the 5 or more years category (HR 0.78; $95 \% \mathrm{CI}$, 0.59 to 1.03 ). Total fracture showed little evidence for association with $\mathrm{CaD}$ supplementation, with HRs from the OS tending to be larger than those from the CT.

To help interpret the hip fracture HRs, it can be noted that the FFQ 5th, 25th, 50th, 75th, and 95th percentiles for dietary calcium (milligram per day) were 291, 512, 738, 1,043 , and 1,650, and for dietary vitamin D (IU/day), and were 47, 96, 149, 221, and 397 in the CT. Corresponding percentiles in the OS were 291, 571, 748, 1,074, and 1,693 for calcium, and 43, 93, 147, 225, and 407 for vitamin D, very similar to those in the CT. It is evident that personal supplement use of $500 \mathrm{mg} /$ day or more calcium and $400 \mathrm{IU} /$ day or more of vitamin D contributes a substantial fraction to the total consumption of these nutrients in study cohorts.

Table 2 also shows that total mortality was somewhat reduced in the first 2 years from randomization among women assigned to active treatment in the CT. This pattern was not evident in later years of follow-up, in corresponding OS analyses, or in combined CT and OS analyses.

Table 3 provides corresponding analyses for cardiovascular diseases. There was little evidence for an adverse influence of $\mathrm{CaD}$ supplementation on the risk for $\mathrm{MI}, \mathrm{CHD}$, total heart disease, stroke, or total cardiovascular disease, from either the CT or OS, or from their combined analysis. In fact, the OS data alone suggest a reduction in total heart disease risk and total cardiovascular disease risk among supplement users.

Table 4 presents corresponding analyses for invasive cancer. Among women with no personal supplements at baseline, there was some evidence for a reduction in breast cancer risk (HR 0.80; $95 \% \mathrm{CI}, 0.66$ to $0.96, P=0.02$ ) and total cancer risk (HR $0.88,95 \% \mathrm{CI}, 0.78$ to $0.98, P=0.03$ ), with little suggestion of HR time trend and with no support from OS data. These patterns were similar in the trial cohort as a whole, but far from significant.

Table 5 presents HRs from the OS for calcium-only and for vitamin D-only supplementation. HRs for calcium plus vitamin D are also repeated from earlier tables for comparative purposes. As mentioned previously, these HRs are subject to residual confounding and other biases, but comparative HRs across supplement types presumably less so. Significant associations were not found for hip fracture or for total fracture for either supplement alone or combined. No associations of calcium or vitamin D with incidence for the specific cancer sites considered or for total invasive cancer were suggested by these Table 5 analyses. A non-significant early elevation in MI incidence with vitamin D is not precisely estimated and is not apparent with the combination of calcium and vitamin D. HR estimates were below one $(P<0.05)$ for calcium alone in relation to $\mathrm{MI}$ and $\mathrm{CHD}$, and as previously mentioned, for $\mathrm{CaD}$ in relation to total heart disease.

Data on adherence to assigned supplement category is important for the interpretation of Table 5 analyses. Following the baseline assessment, data on supplement use in the OS was collected only in conjunction with a clinic visit 3 years later. Of the OS women using calcium plus vitamin $\mathrm{D}$ at baseline, a substantial $80.9 \%$ reported continued use 3 years later, with $10.9 \%$ stopping use of both of these supplements, $6.9 \%$ moving to calcium-only, and $1.4 \%$ moving to vitamin D-only supplements. In contrast among baseline calcium-only users, a remarkable $57.1 \%$ had moved to $\mathrm{CaD}$ preparations by 3 years later, with only $23.7 \%$ still using calcium only, and $17.6 \%$ had stopped using either supplement. Similarly $56.5 \%$ of baseline vitamin $\mathrm{D}$ users had moved to CaD by 3 years later, with only $16.4 \%$ still using vitamin D only. Equally impressive, only $49.9 \%$ of baseline non-users of these supplements retained that status 3 years later, with $38.7 \%$ becoming $\mathrm{CaD}$ users. It is evident that the contrasts presented in Table 5 primarily pertain to $\mathrm{CaD}$ use, and even then the non-user control group evidently becomes quite contaminated over the follow-up period. 
Table 1 Age-adjusted annualized incidence rates in the WHI CaD trial and observational study

\begin{tabular}{|c|c|c|c|c|c|c|c|c|}
\hline & \multicolumn{4}{|c|}{$\mathrm{CaD}$ Trial } & \multicolumn{4}{|c|}{ Observational Study } \\
\hline & \multicolumn{2}{|c|}{ All participants } & \multicolumn{2}{|c|}{$\begin{array}{l}\text { No personal } \\
\text { supplements }\end{array}$} & \multirow[t]{2}{*}{$\begin{array}{l}\text { Non-users of } \\
\text { supplements }\end{array}$} & \multirow[t]{2}{*}{$\begin{array}{l}\text { Calcium+Vitamin } \\
\text { D }\end{array}$} & \multirow[t]{2}{*}{$\begin{array}{l}\text { Calcium } \\
\text { only }\end{array}$} & \multirow[t]{2}{*}{$\begin{array}{l}\text { Vitamin D } \\
\text { only }\end{array}$} \\
\hline & Placebo & $\mathrm{CaD}$ & Placebo & $\mathrm{CaD}$ & & & & \\
\hline Number of women & \multicolumn{8}{|c|}{ Hip fracture } \\
\hline Cases & 199 & 175 & 80 & 68 & 212 & 158 & 55 & 26 \\
\hline Age-adjusted incidence $(\%)^{\mathrm{b}}$ & $\begin{array}{l}0.20 \\
\text { Total fra }\end{array}$ & $\begin{array}{l}0.17 \\
\mathrm{re}\end{array}$ & 0.20 & 0.16 & 0.14 & 0.15 & 0.13 & 0.18 \\
\hline \multirow{2}{*}{$\begin{array}{l}\text { Cases } \\
\text { Age-adjusted incidence }(\%)^{\mathrm{b}}\end{array}$} & 2,158 & 2,102 & 870 & 872 & 3,172 & 2,344 & 834 & 290 \\
\hline & $\begin{array}{l}1.94 \\
\text { Myocard }\end{array}$ & $\begin{array}{l}1.85 \\
\text { infarctio }\end{array}$ & 1.86 & 1.81 & 2.02 & 2.28 & 2.04 & 2.21 \\
\hline Cases & 390 & 411 & 167 & 193 & 433 & 210 & 77 & 40 \\
\hline Age-adjusted incidence $(\%)^{\mathrm{b}}$ & $\begin{array}{l}0.34 \\
\text { Coronary }\end{array}$ & $\begin{array}{l}0.37 \\
\text { eart dises }\end{array}$ & 0.37 & \multicolumn{5}{|c|}{ Coronary heart disease } \\
\hline \multirow{2}{*}{$\begin{array}{l}\text { Cases } \\
\text { Age-adjusted incidence }(\%)^{\mathrm{b}}\end{array}$} & 475 & 499 & 211 & 229 & 545 & 252 & 95 & 50 \\
\hline & \multicolumn{7}{|c|}{ Total heart disease } & 0.36 \\
\hline \multirow{2}{*}{$\begin{array}{l}\text { Cases } \\
\text { Age-adjusted incidence }(\%)^{\mathrm{b}}\end{array}$} & 1,363 & 1,405 & 642 & 621 & 1,602 & 762 & 328 & 132 \\
\hline & $\begin{array}{l}1.24 \\
\text { Stroke }\end{array}$ & 1.28 & \multicolumn{4}{|c|}{ Stroke } & 0.77 & 0.97 \\
\hline Cases & 377 & 362 & 162 & 184 & 471 & 253 & 91 & 38 \\
\hline Age-adjusted incidence $(\%)^{\mathrm{b}}$ & \multicolumn{7}{|c|}{ Total cardiovascular disease } & 0.27 \\
\hline Cases & 1,810 & 1,832 & 813 & 848 & 2,187 & 1,069 & 440 & 181 \\
\hline Age-adjusted incidence $(\%)^{\mathrm{b}}$ & $\begin{array}{l}1.69 \\
\text { Colorect: }\end{array}$ & \multicolumn{7}{|c|}{ Colorectal cancer } \\
\hline Cases & 154 & 168 & 77 & 66 & 174 & 88 & 35 & 9 \\
\hline \multirow[t]{2}{*}{ Age-adjusted incidence $(\%)^{\mathrm{b}}$} & 0.13 & 0.15 & 0.16 & 0.14 & 0.11 & 0.08 & 0.08 & 0.06 \\
\hline & \multicolumn{8}{|c|}{ Breast cancer } \\
\hline Cases & 546 & 528 & 249 & 202 & 665 & 517 & 210 & 60 \\
\hline \multirow[t]{2}{*}{ Age-adjusted incidence $(\%)^{\mathrm{b}}$} & 0.45 & 0.43 & 0.48 & 0.38 & 0.40 & 0.48 & 0.49 & 0.43 \\
\hline & \multicolumn{8}{|c|}{ Total invasive cancer } \\
\hline Cases & 1,411 & 1,366 & 617 & 553 & 1,701 & 1,187 & 474 & 153 \\
\hline Age-adjusted incidence $(\%)^{\mathrm{b}}$ & $\begin{array}{l}1.21 \\
\text { Death }\end{array}$ & 1.16 & 1.28 & 1.11 & 1.07 & 1.11 & 1.12 & 1.12 \\
\hline Cases & 807 & 744 & 338 & 331 & 1,240 & 674 & 266 & 119 \\
\hline Age-adjusted incidence $(\%)^{\mathrm{b}}$ & 0.72 & 0.67 & 0.75 & 0.72 & 0.78 & 0.61 & 0.61 & 0.84 \\
\hline
\end{tabular}

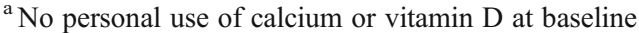

${ }^{\mathrm{b}}$ Adjusted to the 5-year baseline age distribution in the $\mathrm{CaD}$ trial

Table 6 shows HR estimates from the CT using follow-up data from each participating woman only during the period of time that she remained adherent to her assigned active $\mathrm{CaD}$ or placebo pills. Among adherent women, hip fracture risk was lower in the active treatment group both in the overall trial cohort $(P=0.05)$, and in the subset of women without personal supplements $(P=0.04)$. The HR $(95 \% \mathrm{CI})$ among adherent women not using personal supplements was an impressive $0.24(0.07,0.84)$ following 5 or more years of use among women not using personal supplements. The myocardial infarction HR ( $95 \% \mathrm{CI})$ was a non-significant $1.18(0.88,1.59)$ among women not using personal calcium or vitamin D. In contrast, breast and total invasive cancer risks were reduced (both $P=0.01$ ) among women adherent to $\mathrm{CaD}$ 
Table 2 Hazard ratios (bolded) and $95 \%$ confidence intervals for calcium plus vitamin D supplementation from the WHI CaD trial and the Observational Study according to years from supplement initiation: fractures and total deaths

\begin{tabular}{|c|c|c|c|c|c|c|c|c|c|c|}
\hline \multirow[t]{3}{*}{ Years since $\mathrm{CaD}$ initiation } & \multicolumn{4}{|c|}{$\mathrm{CaD}$ trial } & \multirow{2}{*}{\multicolumn{2}{|c|}{$\begin{array}{l}\text { Observational } \\
\text { study }\end{array}$}} & \multicolumn{4}{|c|}{ Combined trial and OS } \\
\hline & \multicolumn{2}{|c|}{ All participants } & \multicolumn{2}{|c|}{$\begin{array}{l}\text { No personal } \\
\text { supplements }\end{array}$} & & & \multicolumn{2}{|c|}{ All participants } & \multicolumn{2}{|c|}{$\begin{array}{l}\text { No personal } \\
\text { supplements }^{\mathrm{a}}\end{array}$} \\
\hline & HR & $95 \% \mathrm{CI}$ & HR & $95 \% \mathrm{CI}$ & HR & $95 \% \mathrm{CI}$ & HR & $95 \% \mathrm{CI}$ & HR & $95 \% \mathrm{CI}$ \\
\hline & \multicolumn{10}{|c|}{ Hip fracture } \\
\hline$<2$ & 0.75 & $0.44,1.26$ & 1.12 & $0.52,2.42$ & 1.41 & $0.44,4.57$ & 0.81 & $0.49,1.31$ & 1.15 & $0.58,2.30$ \\
\hline $2-5$ & 1.01 & $0.73,1.40$ & 1.00 & $0.61,1.65$ & 1.22 & $0.71,2.10$ & 1.03 & $0.77,1.39$ & 1.04 & $0.68,1.57$ \\
\hline$>5$ & 0.82 & $0.61,1.12$ & 0.62 & $0.38,1.00$ & 0.84 & $0.66,1.07$ & 0.78 & $0.59,1.03$ & 0.65 & $0.44,0.98$ \\
\hline Trend test $\mathrm{t}^{\mathrm{b}}$ & 0.96 & & 0.13 & & 0.14 & & 0.43 & & 0.02 & \\
\hline $\mathrm{HR}$ in OS/HR in trial ${ }^{\mathrm{c}}$ & & & & & & & 1.09 & $0.78,1.54$ & 1.28 & $0.82,1.98$ \\
\hline \multirow[t]{2}{*}{ Overall $\mathrm{HR}^{\mathrm{d}}$} & 0.88 & $0.71,1.08$ & 0.86 & $0.62,1.20$ & 0.88 & $0.70,1.11$ & & & & \\
\hline & \multicolumn{10}{|c|}{ Total fracture } \\
\hline$<2$ & 0.96 & $0.86,1.08$ & 0.91 & $0.76,1.10$ & 0.89 & $0.61,1.31$ & 0.95 & $0.85,1.06$ & 0.90 & $0.76,1.06$ \\
\hline $2-5$ & 0.94 & $0.86,1.03$ & 0.97 & $0.84,1.12$ & 1.05 & $0.91,1.22$ & 0.95 & $0.87,1.03$ & 0.98 & $0.87,1.11$ \\
\hline$>5$ & 0.98 & $0.88,1.09$ & 1.03 & $0.87,1.22$ & 1.08 & $1.01,1.14$ & 0.98 & $0.90,1.08$ & 1.02 & $0.90,1.16$ \\
\hline Trend test $\mathrm{t}^{\mathrm{b}}$ & 0.83 & & 0.35 & & 0.42 & & 0.53 & & 0.21 & \\
\hline $\mathrm{HR}$ in OS/HR in trial ${ }^{\mathrm{c}}$ & & & & & & & 1.09 & $0.99,1.21$ & 1.05 & $0.92,1.20$ \\
\hline \multirow[t]{2}{*}{ Overall $\mathrm{HR}^{\mathrm{d}}$} & 0.96 & $0.90,1.02$ & 0.97 & $0.88,1.07$ & 1.07 & $1.01,1.14$ & & & & \\
\hline & Death & & & & & & & & & \\
\hline$<2$ & 0.73 & $0.56,0.96$ & 0.68 & $0.44,1.06$ & 1.49 & $0.79,2.83$ & 0.80 & $0.62,1.04$ & 0.86 & $0.58,1.27$ \\
\hline $2-5$ & 0.87 & $0.75,1.02$ & 0.87 & $0.68,1.11$ & 0.85 & $0.61,1.18$ & 0.87 & $0.76,1.01$ & 0.89 & $0.72,1.09$ \\
\hline$>5$ & 1.01 & $0.87,1.18$ & 1.12 & $0.89,1.40$ & 0.95 & $0.85,1.06$ & 0.99 & $0.86,1.13$ & 1.04 & $0.86,1.26$ \\
\hline Trend test $\mathrm{t}^{\mathrm{b}}$ & 0.03 & & 0.03 & & 0.71 & & 0.09 & & 0.17 & \\
\hline $\mathrm{HR}$ in $\mathrm{OS} / \mathrm{HR}$ in trial ${ }^{\mathrm{c}}$ & & & & & & & 0.97 & $0.82,1.15$ & 0.92 & $0.74,1.14$ \\
\hline Overall $\mathrm{HR}^{\mathrm{d}}$ & 0.91 & $0.83,1.01$ & 0.95 & $0.81,1.11$ & 0.95 & $0.85,1.06$ & & & & \\
\hline
\end{tabular}

${ }^{\mathrm{a}}$ Women using personal calcium or vitamin $\mathrm{D}$ supplements at baseline in the $\mathrm{CaD}$ trial are excluded

${ }^{\mathrm{b}}$ Significance level $(P$ value) for test of no $\mathrm{HR}$ trend across years from $\mathrm{CaD}$ initiation categories, coded as $0,1,2$, respectively

${ }^{\mathrm{c}}$ Overall HR in the OS divided by that in the $\mathrm{CaD}$ trial. This ratio is used as a residual confounding bias correction factor in the OS, in combined trial and cohort study analyses

${ }^{\mathrm{d}}$ Overall HR is the hazard ratio estimate when the HR is assumed not to depend on years from CaD initiation

in these analyses. Analyses that incorporated inverse adherence probability weights were similar with overall test $P$ values among women not using personal supplements of 0.02 for hip fracture, 0.98 for MI, 0.06 for invasive breast cancer, and 0.01 for total invasive cancer.

For completeness, corresponding analyses were also carried out for the complementary subset of 20,275 CT women who reported taking personal supplements of calcium or vitamin D, or both, at the time of WHI enrollment. Overall, HRs $(95 \% \mathrm{CI})$ in this subset were as follows: hip fracture $0.90(0.69,1.17)$, total fracture $0.95(0.87,1.02)$, MI 0.97 $(0.80,1.17)$, CHD $1.01(0.85,1.20)$, total heart disease 1.04 $(0.94,1.16)$, stroke $0.83(0.67,1.01)$, total cardiovascular disease $0.99(0.90,1.08)$, colorectal cancer $1.32(0.98$, $1.79)$, breast cancer $1.09(0.93,1.28)$, total invasive cancer $1.04(0.94,1.15)$, and death $0.91(0.79,1.04)$. None of these HRs differ significantly from unity, though for some outcomes, there is a significant HR difference between the personal supplements and no personal supplements subsets, including stroke $(P=0.04)$, colorectal cancer $(P=0.04)$, breast cancer $(P=0.01)$, and total invasive cancer $(P=0.03)$.

Among women who were adherent to study pills, the overall HRs (95\% CIs) in the personal supplements user subset were as follows: hip fracture $0.85(0.58,1.24)$, total fracture 0.97 (0.87,1.07), MI $0.96(0.74,1.26)$, CHD $1.00(0.79,1.28)$, total heart disease $1.05(0.91,1.21)$, stroke $0.81(0.60,1.08)$, total cardiovascular disease $1.01(0.89,1.14)$, colorectal cancer $1.17(0.78,1.73)$, breast cancer $1.04(0.85,1.29)$, total invasive cancer $1.02(0.90,1.17)$, and death $0.91(0.74,1.11)$. There was significant adherent $\mathrm{HR}$ variation between the personal supplements and no personal supplements subsets only for breast cancer $(P=0.03)$ and total invasive cancer $(P=0.03)$ in these adherence-adjusted analyses. 
Table 3 Hazard ratios (bolded) and $95 \%$ confidence intervals for calcium plus vitamin D supplementation from the WHI CaD trial and Observational Study according to years from supplement initiation: cardiovascular diseases

\begin{tabular}{|c|c|c|c|c|c|c|c|c|c|c|}
\hline \multirow[t]{3}{*}{ Years since $\mathrm{CaD}$ initiation } & \multicolumn{4}{|c|}{$\mathrm{CaD}$ trial } & \multirow{2}{*}{\multicolumn{2}{|c|}{$\begin{array}{l}\text { Observational } \\
\text { study }\end{array}$}} & \multicolumn{4}{|c|}{ Combined trial and OS } \\
\hline & \multicolumn{2}{|c|}{ All participants } & \multicolumn{2}{|c|}{$\begin{array}{l}\text { No personal } \\
\text { supplements }^{\mathrm{a}}\end{array}$} & & & \multicolumn{2}{|c|}{ All participants } & \multicolumn{2}{|c|}{$\begin{array}{l}\text { No personal } \\
\text { supplements }\end{array}$} \\
\hline & HR & $95 \% \mathrm{CI}$ & HR & $95 \% \mathrm{CI}$ & HR & $95 \% \mathrm{CI}$ & HR & $95 \% \mathrm{CI}$ & HR & $95 \% \mathrm{CI}$ \\
\hline & \multicolumn{10}{|c|}{ Myocardial infarction } \\
\hline$<2$ & 1.19 & $0.89,1.59$ & 1.30 & $0.86,1.97$ & 0.56 & $0.14,2.27$ & 1.15 & $0.87,1.51$ & 1.21 & $0.82,1.78$ \\
\hline $2-5$ & 0.97 & $0.78,1.21$ & 1.04 & $0.74,1.47$ & 1.04 & $0.66,1.63$ & 1.00 & $0.82,1.23$ & 1.11 & $0.82,1.49$ \\
\hline$>5$ & 1.01 & $0.80,1.29$ & 1.06 & $0.74,1.50$ & 0.89 & $0.73,1.08$ & 1.00 & $0.80,1.24$ & 1.05 & $0.78,1.41$ \\
\hline Trend test $\mathrm{t}^{\mathrm{b}}$ & 0.46 & & 0.49 & & 0.94 & & 0.49 & & 0.54 & \\
\hline $\mathrm{HR}$ in OS/HR in trial ${ }^{\mathrm{c}}$ & & & & & & & 0.90 & $0.69,1.18$ & 0.85 & $0.61,1.18$ \\
\hline \multirow[t]{2}{*}{ Overall $\mathrm{HR}^{\mathrm{d}}$} & 1.03 & $0.90,1.19$ & 1.11 & $0.90,1.37$ & 0.90 & $0.75,1.09$ & & & & \\
\hline & \multicolumn{10}{|c|}{ Coronary heart disease $\mathrm{e}^{\mathrm{e}}$} \\
\hline$<2$ & 1.10 & $0.85,1.43$ & 1.02 & $0.69,1.49$ & 0.49 & $0.12,2.00$ & 1.07 & $0.83,1.38$ & 0.97 & $0.67,1.38$ \\
\hline $2-5$ & 0.96 & $0.79,1.18$ & 1.06 & $0.78,1.45$ & 1.00 & $0.66,1.63$ & 1.00 & $0.83,1.20$ & 1.10 & $0.84,1.44$ \\
\hline$>5$ & 1.05 & $0.85,1.30$ & 1.02 & $0.75,1.40$ & 0.88 & $0.74,1.05$ & 1.03 & $0.85,1.25$ & 1.02 & $0.78,1.33$ \\
\hline Trend test $\mathrm{t}^{\mathrm{b}}$ & 0.87 & & 0.97 & & 0.88 & & 0.93 & & 0.93 & \\
\hline $\mathrm{HR}$ in OS/HR in trial ${ }^{\mathrm{c}}$ & & & & & & & 0.86 & $0.67,1.10$ & 0.86 & $0.64,1.16$ \\
\hline \multirow[t]{2}{*}{ Overall $\mathrm{HR}^{\mathrm{d}}$} & 1.03 & $0.90,1.17$ & 1.03 & $0.85,1.25$ & 0.88 & $0.74,1.04$ & & & & \\
\hline & \multicolumn{10}{|c|}{ Total heart disease ${ }^{\mathrm{f}}$} \\
\hline$<2$ & 1.05 & $0.90,1.21$ & 1.00 & $0.80,1.24$ & 0.86 & $0.50,1.46$ & 1.04 & $0.90,1.20$ & 0.99 & $0.81,1.21$ \\
\hline $2-5$ & 1.00 & $0.89,1.12$ & 1.05 & $0.88,1.26$ & 0.93 & $0.73,1.17$ & 1.02 & $0.91,1.13$ & 1.05 & $0.90,1.23$ \\
\hline$>5$ & 1.04 & $0.91,1.19$ & 0.98 & $0.81,1.20$ & 0.87 & $0.79,0.97$ & 1.02 & $0.91,1.15$ & 0.99 & $0.84,1.16$ \\
\hline Trend test ${ }^{\mathrm{b}}$ & 0.96 & & 0.91 & & 0.83 & & 0.88 & & 0.91 & \\
\hline $\mathrm{HR}$ in OS/HR in trial ${ }^{\mathrm{c}}$ & & & & & & & 0.86 & $0.75,0.99$ & 0.82 & $0.74,1.05$ \\
\hline \multirow[t]{2}{*}{ Overall $\mathrm{HR}^{\mathrm{d}}$} & 1.02 & $0.95,1.11$ & 1.02 & $0.91,1.14$ & 0.87 & $0.79,0.96$ & & & & \\
\hline & \multicolumn{10}{|c|}{ Stroke $^{\mathrm{g}}$} \\
\hline$<2$ & 0.82 & $0.60,1.12$ & 1.11 & $0.73,1.68$ & 0.47 & $0.12,1.89$ & 0.78 & $0.58,1.05$ & 1.00 & $0.68,1.46$ \\
\hline $2-5$ & 1.06 & $0.84,1.34$ & 1.17 & $0.83,1.65$ & 0.91 & $0.57,1.44$ & 1.03 & $0.84,1.27$ & 1.16 & $0.87,1.55$ \\
\hline$>5$ & 0.92 & $0.73,1.17$ & 1.09 & $0.79,1.52$ & 0.93 & $0.77,1.11$ & 0.98 & $0.80,1.20$ & 1.17 & $0.90,1.54$ \\
\hline Trend test $\mathrm{t}^{\mathrm{b}}$ & 0.71 & & 0.93 & & 0.43 & & 0.37 & & 0.53 & \\
\hline $\mathrm{HR}$ in $\mathrm{OS} / \mathrm{HR}$ in trial ${ }^{\mathrm{c}}$ & & & & & & & 0.96 & $0.75,1.23$ & 0.81 & $0.60,1.09$ \\
\hline \multirow[t]{2}{*}{ Overall $\mathrm{HR}^{\mathrm{d}}$} & 0.95 & $0.82,1.10$ & 1.12 & $0.90,1.39$ & 0.92 & $0.77,1.09$ & & & & \\
\hline & \multicolumn{10}{|c|}{ Total cardiovascular disease $\mathrm{h}^{\mathrm{h}}$} \\
\hline$<2$ & 0.97 & $0.85,1.11$ & 1.02 & $0.84,1.23$ & 0.87 & $0.55,1.35$ & 0.97 & $0.86,1.10$ & 1.02 & $0.85,1.21$ \\
\hline $2-5$ & 0.99 & $0.89,1.10$ & 1.03 & $0.89,1.21$ & 0.91 & $0.74,1.11$ & 1.01 & $0.92,1.10$ & 1.04 & $0.91,1.19$ \\
\hline$>5$ & 1.05 & $0.93,1.18$ & 1.02 & $0.86,1.21$ & 0.86 & $0.79,0.94$ & 1.02 & $0.93,1.13$ & 1.01 & $0.88,1.16$ \\
\hline Trend test ${ }^{\mathrm{b}}$ & 0.37 & & 0.97 & & 0.84 & & 0.42 & & 0.93 & \\
\hline $\mathrm{HR}$ in OS/HR in Trial $^{\mathrm{c}}$ & & & & & & & 0.85 & $0.75,0.96$ & 0.85 & $0.73,0.99$ \\
\hline Overall $\mathrm{HR}^{\mathrm{d}}$ & 1.00 & $0.94,1.07$ & 1.03 & $0.93,1.13$ & 0.86 & $0.79,0.94$ & & & & \\
\hline
\end{tabular}

${ }^{\mathrm{a}}$ Women using personal calcium or vitamin $\mathrm{D}$ supplements at baseline in the $\mathrm{CaD}$ trial are excluded

${ }^{\mathrm{b}}$ Significance level $(P$ value) for test of no $\mathrm{HR}$ trend across years from $\mathrm{CaD}$ initiation categories, coded as $0,1,2$, respectively

${ }^{\mathrm{c}}$ Overall HR in the OS divided by that in the $\mathrm{CaD}$ trial. This ratio is used as a residual confounding bias correction factor in the OS, in combined trial and cohort study analyses

${ }^{\mathrm{d}}$ Overall HR is the hazard ratio estimate when the HR is assumed not to depend on years from CaD initiation

${ }^{\mathrm{e}}$ Non-fatal MI plus CHD death

${ }^{\mathrm{f}} \mathrm{CHD}$ plus revascularization, angina, and congestive heart failure

${ }^{\mathrm{g}}$ Combined ischemic and hemorrhagic stroke

${ }^{\mathrm{h}}$ Total heart disease plus stroke, carotid artery disease, and peripheral vascular disease 
Table 4 Hazard ratios (bolded) and $95 \%$ confidence intervals for calcium plus vitamin D supplementation from the WHI CaD trial and Observational Study according to years from supplement initiation: invasive cancer

\begin{tabular}{|c|c|c|c|c|c|c|c|c|c|c|}
\hline \multirow[t]{3}{*}{ Years since $\mathrm{CaD}$ initiation } & \multicolumn{4}{|c|}{$\mathrm{CaD}$ trial } & \multirow{2}{*}{\multicolumn{2}{|c|}{$\begin{array}{l}\text { Observational } \\
\text { study }\end{array}$}} & \multicolumn{4}{|c|}{ Combined trial and OS } \\
\hline & \multicolumn{2}{|c|}{ All participants } & \multicolumn{2}{|c|}{$\begin{array}{l}\text { No personal } \\
\text { supplements }\end{array}$} & & & \multicolumn{2}{|c|}{ All participants } & \multicolumn{2}{|c|}{$\begin{array}{l}\text { No personal } \\
\text { supplements }^{\mathrm{a}}\end{array}$} \\
\hline & HR & $95 \% \mathrm{CI}$ & HR & $95 \% \mathrm{CI}$ & HR & $95 \% \mathrm{CI}$ & HR & $95 \% \mathrm{CI}$ & HR & $95 \% \mathrm{CI}$ \\
\hline & \multicolumn{10}{|c|}{ Colorectal cancer } \\
\hline$<2$ & 0.89 & $0.57,1.38$ & 0.71 & $0.35,1.44$ & 0.94 & $0.23,3.87$ & 0.92 & $0.60,1.40$ & 0.75 & $0.39,1.45$ \\
\hline $2-5$ & 1.00 & $0.71,1.41$ & 0.75 & $0.45,1.24$ & 0.80 & $0.39,1.65$ & 1.02 & $0.74,1.41$ & 0.78 & $0.50,1.21$ \\
\hline$>5$ & 1.30 & $0.88,1.92$ & 0.99 & $0.56,1.77$ & 0.83 & $0.60,1.14$ & 1.23 & $0.87,1.74$ & 0.90 & $0.56,1.45$ \\
\hline Trend test ${ }^{\mathrm{b}}$ & 0.19 & & 0.44 & & 0.96 & & 0.26 & & 0.57 & \\
\hline $\mathrm{HR}$ in OS/HR in trial ${ }^{\mathrm{d}}$ & & & & & & & 0.69 & $0.45,1.07$ & 0.94 & $0.55,1.59$ \\
\hline \multirow[t]{2}{*}{ Overall $\mathrm{HR}^{\mathrm{d}}$} & 1.06 & $0.85,1.32$ & 0.81 & $0.58,1.13$ & 0.83 & $0.61,1.12$ & & & & \\
\hline & \multicolumn{10}{|c|}{ Breast cancer } \\
\hline$<2$ & 1.00 & $0.79,1.27$ & 0.98 & $0.68,1.42$ & 0.90 & $0.44,1.83$ & 0.97 & $0.78,1.22$ & 0.88 & $0.64,1.22$ \\
\hline $2-5$ & 0.98 & $0.82,1.18$ & 0.75 & $0.56,1.00$ & 1.05 & $0.78,1.41$ & 0.95 & $0.81,1.12$ & 0.75 & $0.59,0.95$ \\
\hline$>5$ & 0.89 & $0.72,1.11$ & 0.73 & $0.52,1.02$ & 1.14 & $1.00,1.30$ & 0.95 & $0.80,1.14$ & 0.80 & $0.62,1.02$ \\
\hline Trend test ${ }^{\mathrm{b}}$ & 0.45 & & 0.26 & & 0.42 & & 0.89 & & 0.87 & \\
\hline $\mathrm{HR}$ in OS/HR in trial ${ }^{\mathrm{c}}$ & & & & & & & 1.18 & $0.96,1.45$ & 1.42 & $1.09,1.84$ \\
\hline \multirow[t]{2}{*}{ Overall $\mathrm{HR}^{\mathrm{d}}$} & 0.96 & $0.85,1.08$ & 0.80 & $0.66,0.96$ & 1.12 & $0.99,1.28$ & & & & \\
\hline & \multicolumn{10}{|c|}{ Total invasive cancer } \\
\hline$<2$ & 0.96 & $0.83,1.12$ & 0.96 & $0.76,1.22$ & 0.87 & $0.56,1.36$ & 0.95 & $0.82,1.09$ & 0.91 & $0.74,1.12$ \\
\hline $2-5$ & 0.94 & $0.84,1.06$ & 0.82 & $0.69,0.98$ & 0.99 & $0.82,1.20$ & 0.94 & 0.85 .1 .05 & 0.84 & $0.73,0.97$ \\
\hline$>5$ & 0.99 & $0.87,1.13$ & 0.89 & $0.73,1.09$ & 1.04 & $0.95,1.13$ & 0.99 & $0.89,1.11$ & 0.90 & $0.77,1.05$ \\
\hline Trend test $\mathrm{t}^{\mathrm{b}}$ & 0.77 & & 0.73 & & 0.31 & & 0.48 & & 0.72 & \\
\hline $\mathrm{HR}$ in $\mathrm{OS} / \mathrm{HR}$ in trial ${ }^{\mathrm{d}}$ & & & & & & & 1.04 & $0.91,1.18$ & 1.15 & $0.97,1.35$ \\
\hline Overall $\mathrm{HR}^{\mathrm{d}}$ & 0.96 & $0.89,1.04$ & 0.88 & $0.78,0.98$ & 1.03 & $0.95,1.11$ & & & & \\
\hline
\end{tabular}

${ }^{\mathrm{a}}$ Women using personal calcium or vitamin $\mathrm{D}$ supplements at baseline in the $\mathrm{CaD}$ trial are excluded

${ }^{\mathrm{b}}$ Significance level $(P$ value) for test of no $\mathrm{HR}$ trend across years from $\mathrm{CaD}$ initiation categories, coded as $0,1,2$, respectively

${ }^{\mathrm{c}}$ Overall HR in the OS divided by that in the $\mathrm{CaD}$ trial. This ratio is used as a residual confounding bias correction factor in the OS, in combined trial and cohort study analyses

${ }^{\mathrm{d}}$ Overall HR is the hazard ratio estimate when the HR is assumed not to depend on years from CaD initiation

Concerning urinary tract stones, as previously reported $[1,7] 449$ women $(0.35 \%)$ in the group randomized to $\mathrm{CaD}$ and 381 women $(0.30 \%)$ in the placebo group developed urinary tract stones during the trial intervention period, leading to an HR (95\% CI) of $1.17(1.02,1.34)$. Among adherent women, the HR $(95 \% \mathrm{CI})$ was $1.21(0.98,1.50)$. These analyses were repeated here, separately for the no personal supplements and personal supplements groups.

In the no personal supplements subset, the HR $(95 \% \mathrm{CI})$ was $1.08(0.88,1.32)$ based on 199 women developing urinary tract stones in the active treatment group and 180 in the placebo group. The corresponding HR $(95 \% \mathrm{CI})$ in the personal supplements subset was $1.23(1.01,1.48)$ based on 239 and 197 women with stones in the active and placebo groups. The HRs did not differ significantly $(P=0.39)$ between the two subsets. Among adherent women, the HR $(95 \% \mathrm{CI})$ was $1.21(0.87,1.69)$ in the no personal supplements group and $1.19(0.89,1.58)$ in the personal supplements group, with no evidence $(P=0.87)$ for difference between the HRs for adherent women between the two subsets.

Subset analyses by age group or by prior CVD history were generally similar to those for the overall cohorts for the various outcomes considered above and are not shown.

\section{Discussion}

Our further analyses of WHI calcium and vitamin D trial data, through the end of the intervention period, along with corresponding and combined analyses using the WHI observational study, yields few clear clinical effects for daily $1,000 \mathrm{mg}$ calcium plus $400 \mathrm{IU}$ of vitamin D.

The strongest evidence for benefit is for hip fracture where calcium and vitamin D supplementation yielded a 
Table 5 Hazard ratios (bolded) and $95 \%$ confidence intervals for supplementation of calcium only and vitamin D only and for calcium and vitamin D combined from the WHI Observational Study, according to years from supplement initiation

\begin{tabular}{|c|c|c|c|c|c|c|c|c|c|c|c|c|}
\hline \multirow{2}{*}{$\begin{array}{l}\text { Years from } \\
\text { Supplement } \\
\text { Initiation }\end{array}$} & \multicolumn{2}{|c|}{ Calcium only } & \multicolumn{2}{|c|}{ Vitamin D only } & \multicolumn{2}{|l|}{$\mathrm{CaD}$} & \multicolumn{2}{|c|}{ Calcium only } & \multicolumn{2}{|c|}{ Vitamin D only } & \multicolumn{2}{|l|}{$\mathrm{CaD}$} \\
\hline & HR & $95 \% \mathrm{CI}$ & HR & $95 \% \mathrm{CI}$ & HR & $95 \% \mathrm{CI}$ & HR & $95 \% \mathrm{CI}$ & HR & $95 \% \mathrm{CI}$ & HR & $95 \% \mathrm{CI}$ \\
\hline & \multicolumn{6}{|c|}{ Hip fracture } & \multicolumn{6}{|c|}{ Total fracture } \\
\hline$<2$ & 2.85 & $0.67,12.12$ & 2.51 & $0.34,18.60$ & 1.41 & $0.44,4.57$ & 0.69 & $0.37,1.29$ & 1.53 & $0.82,2.86$ & 0.89 & $0.61,1.31$ \\
\hline $2-5$ & 0.60 & $0.19,1.89$ & 1.44 & $0.45,4.56$ & 1.22 & $0.71,2.10$ & 0.93 & $0.75,1.16$ & 1.19 & $0.88,1.61$ & 1.05 & $0.91,1.22$ \\
\hline$>5$ & 0.82 & $0.58,1.15$ & 1.17 & $0.73,1.86$ & 0.84 & $0.66,1.07$ & 1.00 & $0.91,1.09$ & 1.02 & $0.88,1.18$ & 1.08 & $1.01,1.14$ \\
\hline Trend test ${ }^{\mathrm{a}}$ & 0.49 & & 0.48 & & 0.14 & & 0.26 & & 0.15 & & 0.42 & \\
\hline \multirow[t]{2}{*}{ Overall $\mathrm{HR}^{\mathrm{b}}$} & 0.82 & $0.59,1.14$ & 1.23 & $0.80,1.88$ & 0.88 & $0.70,1.11$ & 0.99 & $0.91,1.07$ & 1.06 & $0.93,1.20$ & 1.07 & $1.01,1.14$ \\
\hline & \multicolumn{6}{|c|}{ Myocardial infarction } & \multicolumn{6}{|c|}{ Coronary heart disease } \\
\hline$<2$ & 0.85 & $0.21,3.48$ & 1.72 & $0.42,7.06$ & 0.56 & $0.14,2.27$ & 0.77 & $0.19,3.13$ & 1.59 & $0.39,6.48$ & 0.49 & $0.12,2.00$ \\
\hline $2-5$ & 0.87 & $0.44,1.69$ & 1.28 & $0.57,2.89$ & 1.04 & $0.66,1.63$ & 0.96 & $0.54,1.72$ & 1.07 & $0.48,2.41$ & 1.00 & $0.66,1.53$ \\
\hline$>5$ & 0.71 & $0.53,0.97$ & 0.99 & $0.67,1.47$ & 0.89 & $0.73,1.08$ & 0.74 & $0.56,0.97$ & 1.02 & $0.72,1.45$ & 0.88 & $0.74,1.05$ \\
\hline Trend test $\mathrm{t}^{\mathrm{a}}$ & 0.60 & & 0.38 & & 0.94 & & 0.53 & & 0.61 & & 0.88 & \\
\hline \multirow[t]{2}{*}{ Overall $\mathrm{HR}^{\mathrm{b}}$} & 0.74 & $0.56,0.97$ & 1.06 & $0.75,1.51$ & 0.90 & $0.75,1.09$ & 0.74 & $0.58,0.95$ & 1.04 & $0.76,1.43$ & 0.88 & $0.74,1.04$ \\
\hline & \multicolumn{6}{|c|}{ Total heart disease } & \multicolumn{6}{|c|}{ Stroke } \\
\hline$<2$ & 1.07 & $0.57,2.00$ & 1.32 & $0.59,2.96$ & 0.86 & $0.50,1.46$ & 0.84 & $0.21,3.41$ & $\mathrm{NA}^{\mathrm{c}}$ & & 0.47 & $0.12,1.89$ \\
\hline $2-5$ & 1.05 & $0.78,1.42$ & 0.83 & $0.51,1.36$ & 0.93 & $0.73,1.17$ & 1.04 & $0.58,1.86$ & 0.77 & $0.29,2.07$ & 0.91 & $0.57,1.44$ \\
\hline$>5$ & 0.95 & $0.82,1.10$ & 0.97 & $0.78,1.20$ & 0.87 & $0.79,0.97$ & 0.81 & $0.62,1.07$ & 0.82 & $0.55,1.23$ & 0.93 & $0.77,1.11$ \\
\hline Trend test $^{\mathrm{a}}$ & 0.47 & & 0.82 & & 0.83 & & 0.47 & & 0.45 & & 0.28 & \\
\hline \multirow[t]{2}{*}{ Overall $\mathrm{HR}^{\mathrm{b}}$} & 0.95 & $0.83,1.08$ & 0.96 & $0.79,1.16$ & 0.87 & $0.79,0.96$ & 0.84 & $0.66,1.07$ & 0.80 & $0.55,1.15$ & 0.92 & $0.77,1.09$ \\
\hline & \multicolumn{6}{|c|}{ Total cardiovascular disease } & \multicolumn{6}{|c|}{ Colorectal cancer } \\
\hline$<2$ & 0.99 & $0.57,1.72$ & 1.09 & $0.52,2.30$ & 0.87 & $0.55,1.35$ & 1.03 & $0.14,7.47$ & $\mathrm{NA}^{\mathrm{c}}$ & & 0.94 & $0.23,3.87$ \\
\hline $2-5$ & 1.02 & $0.78,1.32$ & 0.90 & $0.60,1.34$ & 0.91 & $0.74,1.11$ & 1.05 & $0.42,2.58$ & 0.95 & $0.23,3.88$ & 0.80 & $0.39,1.65$ \\
\hline$>5$ & 0.89 & $0.79,1.01$ & 0.92 & $0.76,1.10$ & 0.86 & $0.79,0.94$ & 1.01 & $0.66,1.55$ & 0.64 & $0.28,1.46$ & 0.83 & $0.60,1.14$ \\
\hline Trend test $\mathrm{t}^{\mathrm{a}}$ & 0.31 & & 0.81 & & 0.84 & & 0.96 & & 0.91 & & 0.96 & \\
\hline \multirow[t]{2}{*}{ Overall $\mathrm{HR}^{\mathrm{b}}$} & 0.89 & $0.80,1.60$ & 0.92 & $0.78,1.09$ & 0.86 & $0.79,0.94$ & 1.02 & $0.69,1.51$ & 0.67 & $0.33,1.36$ & 0.83 & $0.61,1.12$ \\
\hline & \multicolumn{6}{|c|}{ Breast cancer } & \multicolumn{6}{|c|}{ Total invasive cancer } \\
\hline$<2$ & 0.44 & $0.11,1.76$ & 1.74 & $0.55,5.48$ & 0.90 & $0.44,1.83$ & 0.43 & $0.18,1.04$ & 0.95 & $0.39,2.30$ & 0.87 & $0.56,1.36$ \\
\hline $2-5$ & 1.15 & $0.76,1.72$ & 1.18 & $0.85,2.71$ & 1.05 & $0.78,1.41$ & 1.13 & $0.88,1.46$ & 0.81 & $0.51,1.29$ & 0.99 & $0.82,1.20$ \\
\hline$>5$ & 1.18 & $0.98,1.42$ & 1.11 & $0.62,1.23$ & 1.14 & $1.00,1.30$ & 1.12 & $0.99,1.26$ & 1.05 & $0.87,1.28$ & 1.04 & $0.95,1.13$ \\
\hline Trend test $\mathrm{t}^{\mathrm{a}}$ & 0.30 & & 0.07 & & 0.42 & & 0.18 & & 0.40 & & 0.31 & \\
\hline \multirow[t]{2}{*}{ Overall $\mathrm{HR}^{\mathrm{b}}$} & 1.15 & $0.97,1.37$ & 1.01 & $0.75,1.34$ & 1.12 & 0.99 .1 .28 & 1.10 & $0.98,1.22$ & 1.01 & $0.85,1.20$ & 1.03 & $0.95,1.11$ \\
\hline & \multicolumn{12}{|l|}{ Death } \\
\hline$<2$ & 0.32 & $0.05,2.31$ & 1.31 & $0.32,5.31$ & 1.49 & $0.79,2.83$ & & & & & & \\
\hline $2-5$ & 1.05 & $0.69,1.60$ & 0.78 & $0.39,1.57$ & 0.85 & $0.61,1.18$ & & & & & & \\
\hline$>5$ & 0.93 & $0.80,1.09$ & 1.09 & $0.87,1.35$ & 0.95 & $0.85,1.06$ & & & & & & \\
\hline Trend test ${ }^{\mathrm{a}}$ & 0.81 & & 0.60 & & 0.71 & & & & & & & \\
\hline Overall $\mathrm{HR}^{\mathrm{b}}$ & 0.94 & $0.81,1.09$ & 1.06 & $0.86,1.30$ & 0.95 & $0.85,1.06$ & & & & & & \\
\hline
\end{tabular}

${ }^{\text {a }}$ Significance level ( $P$ value) for test of no $\mathrm{HR}$ trend across years from $\mathrm{CaD}$ initiation categories, coded as $0,1,2$, respectively

${ }^{\mathrm{b}}$ Overall HR is the hazard ratio estimate when the HR is assumed not to depend on years from $\mathrm{CaD}$ initiation

${ }^{\mathrm{c}} \mathrm{NA}$ - too few events for reliable HR calculation

noteworthy reduction after 5 years of treatment among women not taking personal supplements, with HR $(95 \%$ CI) of $0.62(0.38,1.00)$. It is important to note that hip fracture was the sole primary outcome in the $\mathrm{CaD}$ trial, reducing multiple testing limitations. Nevertheless, a cautious interpretation is needed since this is a finding in the no personal supplements subset, while the corresponding overall trial result (HR of $0.82,95 \% \mathrm{CI}$ of 0.61 to 1.12 ) is not significant. However, the likelihood of a hip fracture risk reduction is enhanced by a significant $(P=0.02)$ trend of reducing HR with duration of supplementation in the no personal supplements group and by nominally significant 
Table 6 Hazard ratios (bolded) and $95 \%$ confidence intervals for calcium and vitamin D supplementation in the WHI CaD trial according to duration of supplementation among women adherent to their assigned study pills

\begin{tabular}{|c|c|c|c|c|c|c|c|c|}
\hline \multirow{2}{*}{$\begin{array}{l}\text { Duration of } \mathrm{CaD} \\
\text { supplementation }\end{array}$} & \multicolumn{2}{|c|}{ All participants } & \multicolumn{2}{|c|}{ No personal supplements } & \multicolumn{2}{|c|}{ All participants } & \multicolumn{2}{|c|}{ No personal supplements } \\
\hline & HR & $95 \% \mathrm{CI}$ & HR & $95 \% \mathrm{CI}$ & HR & $95 \% \mathrm{CI}$ & HR & $95 \% \mathrm{CI}$ \\
\hline & \multicolumn{4}{|c|}{ Hip fracture } & \multicolumn{4}{|c|}{ Total fracture } \\
\hline$<2$ & 0.62 & $0.33,1.15$ & 0.88 & $0.32,2.43$ & 0.95 & $0.83,1.08$ & 0.87 & $0.70,1.06$ \\
\hline $2-5$ & 0.83 & $0.50,1.37$ & 0.66 & $0.28,1.52$ & 0.90 & $0.79,1.03$ & 0.91 & $0.73,1.13$ \\
\hline$>5$ & 0.73 & $0.44,1.23$ & 0.24 & $0.07,0.84$ & 0.98 & $0.82,1.16$ & 0.95 & $0.71,1.27$ \\
\hline Trend test ${ }^{\mathrm{a}}$ & 0.74 & & 0.12 & & 0.89 & & 0.61 & \\
\hline \multirow[t]{2}{*}{ Overall $\mathrm{HR}^{\mathrm{b}}$} & 0.73 & $0.54,1.00$ & 0.55 & $0.32,0.97$ & 0.94 & $0.86,1.02$ & 0.90 & $0.78,1.03$ \\
\hline & \multicolumn{4}{|c|}{ Myocardial infarction } & \multicolumn{4}{|c|}{ Coronary heart disease } \\
\hline$<2$ & 1.23 & $0.90,1.69$ & 1.37 & $0.86,2.18$ & 1.21 & $0.90,1.62$ & 1.14 & $0.74,1.76$ \\
\hline $2-5$ & 1.07 & $0.78,1.49$ & 1.35 & $0.81,2.26$ & 1.01 & $0.74,1.36$ & 1.26 & $0.78,2.01$ \\
\hline$>5$ & 0.82 & $0.55,1.21$ & 0.78 & $0.43,1.41$ & 0.88 & $0.61,1.26$ & 0.82 & $0.47,1.41$ \\
\hline Trend test $\mathrm{t}^{\mathrm{a}}$ & 0.12 & & 0.17 & & 0.17 & & 0.40 & \\
\hline \multirow[t]{2}{*}{ Overall $\mathrm{HR}^{\mathrm{b}}$} & 1.06 & $0.87,1.29$ & 1.18 & $0.88,1.59$ & 1.04 & $0.87,1.25$ & 1.08 & $0.82,1.42$ \\
\hline & \multicolumn{4}{|c|}{ Total heart disease } & \multicolumn{4}{|c|}{ Stroke } \\
\hline$<2$ & 1.06 & $0.89,1.25$ & 1.05 & $0.82,1.34$ & 0.81 & $0.57,1.14$ & 1.01 & $0.63,1.64$ \\
\hline $2-5$ & 1.01 & $0.85,1.19$ & 1.00 & $0.77,1.31$ & 1.19 & $0.85,1.67$ & 1.73 & $0.99,3.01$ \\
\hline$>5$ & 1.04 & $0.84,1.30$ & 0.92 & $0.66,1.29$ & 0.88 & $0.57,1.36$ & 0.92 & $0.48,1.76$ \\
\hline Trend test ${ }^{\mathrm{a}}$ & 0.87 & & 0.56 & & 0.60 & & 0.96 & \\
\hline \multirow[t]{2}{*}{ Overall $\mathrm{HR}^{\mathrm{b}}$} & 1.03 & $0.93,1.15$ & 1.00 & $0.86,1.18$ & 0.96 & $0.78,1.19$ & 1.18 & $0.86,1.62$ \\
\hline & \multicolumn{4}{|c|}{ Total cardiovascular disease } & \multicolumn{4}{|c|}{ Colorectal cancer } \\
\hline$<2$ & 0.98 & $0.85,1.14$ & 1.04 & $0.84,1.29$ & 0.91 & $0.56,1.47$ & 0.73 & $0.34,1.60$ \\
\hline $2-5$ & 1.04 & $0.89,1.20$ & 1.07 & $0.84,1.34$ & 1.01 & $0.62,1.66$ & 0.92 & $0.44,1.93$ \\
\hline$>5$ & 1.06 & $0.88,1.29$ & 0.98 & $0.73,1.31$ & 1.10 & $0.59,2.07$ & 0.71 & $0.27,1.88$ \\
\hline Trend test ${ }^{\mathrm{a}}$ & 0.49 & & 0.77 & & 0.63 & & 0.98 & \\
\hline \multirow[t]{2}{*}{ Overall $\mathrm{HR}^{\mathrm{b}}$} & 1.02 & $0.93,1.12$ & 1.04 & $0.90,1.19$ & 0.99 & $0.73,1.34$ & 0.80 & $0.50,1.27$ \\
\hline & \multicolumn{4}{|c|}{ Breast cancer } & \multicolumn{4}{|c|}{ Total invasive cancer } \\
\hline$<2$ & 0.96 & $0.73,1.27$ & 0.90 & $0.58,1.39$ & 0.97 & $0.82,1.14$ & 0.94 & $0.71,1.23$ \\
\hline $2-5$ & 0.85 & $0.66,1.10$ & 0.60 & $0.39,0.92$ & 0.86 & $0.74,1.02$ & 0.70 & $0.53,0.92$ \\
\hline$>5$ & 0.88 & $0.63,1.24$ & 0.67 & $0.39,1.17$ & 0.95 & $0.77,1.18$ & 0.79 & $0.56,1.11$ \\
\hline Trend test $^{\mathrm{a}}$ & 0.64 & & 0.35 & & 0.81 & & 0.35 & \\
\hline \multirow[t]{2}{*}{ Overall $\mathrm{HR}^{\mathrm{b}}$} & 0.90 & $0.76,1.06$ & 0.71 & $0.55,0.93$ & 0.92 & $0.83,1.02$ & 0.80 & $0.68,0.95$ \\
\hline & \multicolumn{4}{|c|}{ Death } & & & & \\
\hline$<2$ & 0.78 & $0.57,1.08$ & 0.69 & $0.41,1.16$ & & & & \\
\hline $2-5$ & 0.81 & $0.63,1.04$ & 0.82 & $0.54,1.26$ & & & & \\
\hline$>5$ & 1.06 & $0.80,1.41$ & 1.02 & $0.65,1.59$ & & & & \\
\hline Trend test ${ }^{\mathrm{a}}$ & 0.14 & & 0.26 & & & & & \\
\hline Overall $\mathrm{HR}^{\mathrm{b}}$ & 0.88 & $0.75,1.03$ & 0.85 & $0.65,1.11$ & & & & \\
\hline
\end{tabular}

${ }^{\text {a }}$ Significance level $(P$ value) for test of no HR trend across years from $\mathrm{CaD}$ initiation categories, coded as $0,1,2$, respectively

${ }^{\mathrm{b}}$ Overall HR is the hazard ratio estimate when the HR is assumed not to depend on duration from supplementation

risk reductions over the entire follow-up period among adherent women, both in the overall trial cohort and in the no personal supplements subset (Table 6). For example, these adherence-adjusted analyses yield an HR $(95 \% \mathrm{CI})$ of $0.24(0.07,0.84)$ following 5 or more years of use among women in the no personal supplements group, suggesting that the public health implications of supplementation could be substantial. Moreover, the biological plausibility of this finding is also supported by higher $(P<0.01)$ hip bone mineral density (BMD) in the active treatment versus placebo group at 2, 5, and 8 years of follow-up [1]. Supplementary Figure 1 shows average hip, spine, and whole body BMD at baseline, and at 2, 5, and 8 years later, by randomization group, overall, and in the subset of women not using personal supplements, 
with and without restriction to women adhering to assigned study pills. A larger hip BMD in the intervention group is evident overall, and among women not taking personal supplements, and the difference is enhanced among adherent women.

WHI data provide little support for an influence of calcium and vitamin D supplementation on coronary heart disease risk or cardiovascular disease risk more generally. Women randomized to $\mathrm{CaD}$ do not have a significantly elevated risk of MI, CHD, total heart disease, stroke or total cardiovascular disease, either overall or in the subset not using supplements at baseline. Furthermore, any suggestion of an early MI elevation is dampened by multiple testing considerations, since none of the several cardiovascular disease categories considered were among the designated primary or secondary trial outcome and any such suggestion was not enhanced by restriction to women who adhered to study medications. Also, there was no suggested MI elevation in the OS. Moreover, in the analyses of 754 women in the $\mathrm{CaD}$ trial who underwent cardiac CT scans for assessment of coronary artery calcium (CAC) scores at trial completion, no association between $\mathrm{CaD}$ supplementation and CAC was observed, irrespective of baseline intake of calcium and/or vitamin D [31]. However, given concern about an elevation in MI with calcium use based on other data sources [8], one should keep in mind the possibility of an early MI elevation, but this hypothesis derives little support from WHI data.

The analyses of $\mathrm{CaD}$ trial data suggest possible reductions for invasive cancer with supplementation [3, 8]. Such HR reductions are nominally significant for invasive breast cancer $(P=0.02)$ and for total invasive cancer $(P=0.03)$ among women not using personal supplements, and these reductions persisted following restriction to adherent women. However, corresponding HR reductions were not significant for the trial cohort as a whole. The fact that HRs for both breast cancer and total cancer differed significantly between the personal supplements and no personal supplements groups could reflect HRs that are below unity at lower calcium and vitamin D doses, and that flatten out at larger doses so that women using personal supplements may have already achieved any cancer risk reduction from supplementation, with little or no further benefit from further supplementation. While this possibility is intriguing, and potentially of public health importance, breast and total cancer were not among the designated primary or secondary outcomes for the $\mathrm{CaD}$, so multiple testing considerations, in conjunction with subset analysis and other [3] considerations cause us to take a cautious interpretation of these analyses. Hence, we regard the WHI data as merely suggestive of invasive breast and total invasive cancer risk reduction with available data.

Consistent with our previous report [7], we find no statistically significant association between $\mathrm{CaD}$ supplementation and death in the $\mathrm{CaD}$ trial overall or in the subgroup not using personal supplements. There was no evidence in either the $\mathrm{CaD}$ trial or the OS that long-term ( $\geq 5$ years) $\mathrm{CaD}$ supplementation reduced the risk of death. Specifically, the $\mathrm{CaD}$ intervention did not affect death from coronary heart disease where the hazard ratio was $0.99(95 \% \mathrm{CI}, 0.71,1.38)$ [7].

With this background, the only documented risk associated with the randomized intervention in the $\mathrm{CaD}$ trial is a modest elevation (HR of 1.17, $95 \%$ CI from 1.02 to 1.34 ) in urinary tract stone occurrence that did not differ significantly between the personal supplements and no personal supplements subsets.

Observational data have several limitations in addressing these types of research questions. For outcomes, such as hip fractures and heart disease, where calcium and/or vitamin D from foods or supplements may have developed a reputation as potential disease preventatives, observational studies not only need to control for standard confounding factors, but also for factors related to confounding by indication since persons at elevated risk for these diseases may self-select, or preferentially be prescribed, these supplements. On the other hand, women using dietary supplements are typically health conscious and may have favorable risk factor profiles for some study diseases. The extent to which confounding control efforts are adequate in such challenging settings is usually unknown. In fact, we see evidence of differing HRs for calcium plus vitamin D from the $\mathrm{CaD}$ trial and the $\mathrm{OS}$ in Tables 2, 3, and 4 (i.e., $\mathrm{HR}$ in OS/HR in CT differs from unity) for several outcomes including total fracture, total heart disease, total cardiovascular disease, and breast cancer. Even though some of these differences may arise from differential adherence to supplementation, they reinforce the need for a cautious approach to interpreting observational associations of this type. Here, inclusion of the OS data did not lead to any new findings but did contribute to evidence for a hip fracture reduction, via our conservative combined clinical trial and observational study data analyses.

Even though there is intense interest in the health effects of supplementation using higher doses than 400 IU/day of vitamin D, the WHI cohorts simply do not have enough women using higher doses to attempt any meaningful analyses.

In summary, WHI clinical trial data are mostly null or inconclusive concerning the health effects of calcium and vitamin D supplementation. Compared to previous WHI reports, the analyses presented here include a focus on whether or not women were using personal supplements at the time of WHI enrollment and a focus on temporal HR patterns across the trial intervention period, leading to more compelling evidence for a hip fracture risk reduction benefit that is somewhat offset by a previously reported elevation in urinary tract stones. Ultimate health benefits versus risks assessment for this intervention could be favorably affected by a reduction in invasive cancer, though evidence is only suggestive at present, while data from other sources suggesting adverse cardiovascular effects of calcium supplementation do not receive support from WHI data. Decisions concerning supplementation with this 
combination may depend on many factors, including age and sex, and importantly, risk for outcomes affected by $\mathrm{CaD}$. Given the widespread use of these supplements in the USA and elsewhere, it will be important to continue to acquire data to refine estimates of health benefits and risks among postmenopausal women, and other societal groups, and to extend results to other supplementation doses.

Acknowledgments Program Office: (National Heart, Lung, and Blood Institute, Bethesda, Maryland) Jacques Rossouw, Shari Ludlam, Dale Burwen, Joan McGowan, Leslie Ford, and Nancy Geller

Clinical Coordinating Center: Clinical Coordinating Center: (Fred Hutchinson Cancer Research Center, Seattle, WA) Garnet Anderson, Ross Prentice, Andrea LaCroix, and Charles Kooperberg

Investigators and Academic Centers: (Brigham and Women's Hospital, Harvard Medical School, Boston, MA) JoAnn E. Manson; (MedStar Health Research Institute/Howard University, Washington, DC) Barbara V. Howard; (Stanford Prevention Research Center, Stanford, CA) Marcia L. Stefanick; (The Ohio State University, Columbus, OH) Rebecca Jackson; (University of Arizona, Tucson/Phoenix, AZ) Cynthia A. Thomson; (University at Buffalo, Buffalo, NY) Jean Wactawski-Wende; (University of Florida, Gainesville/Jacksonville, FL) Marian Limacher; (University of Iowa, Iowa City/Davenport, IA) Robert Wallace; (University of Pittsburgh, Pittsburgh, PA) Lewis Kuller; (Wake Forest University School of Medicine, Winston-Salem, NC) Sally Shumaker

Women's Health Initiative Memory Study: (Wake Forest University School of Medicine, Winston-Salem, NC) Sally Shumaker

For a list of all the investigators who have contributed to WHI science, please visit: https://cleo.whi.org/researchers/Documents $\% 20 \% 20 \mathrm{Wri}$ te $\% 20 \mathrm{a} \% 20$ Paper/WHI\%20Investigator\%20Long\%20List.pdf

Funding/Support This work was partially supported by a grant from the National Osteoporosis Foundation. This sponsor was not involved in decisions concerning data analyses to be conducted, their interpretation, or in manuscript development. The WHI program is funded by the National Heart, Lung, and Blood Institute, National Institutes of Health, U.S. Department of Health and Human Services through contracts N01WH22110, 24152, 32100-2, 32105-6, 32108-9, 32111-13, 32115, 32118-32119, 32122, 42107-26, 42129-32, and 44221. Related data analytic methodology work was supported by NIH grant CA53996.

\section{Conflicts of interest None.}

Open Access This article is distributed under the terms of the Creative Commons Attribution License which permits any use, distribution, and reproduction in any medium, provided the original author(s) and the source are credited.

\section{References}

1. Jackson RD, LaCroix AZ, Gass M, Wallace RB, Robbins J, Lewis CE, Bassford T, Beresford SA, Black HR, Blanchette P, Bonds DE, Brunner RL, Brzyski RG, Caan B, Cauley JA, Chlebowski RT, Cummings SR, Granek I, Hays J, Heiss G, Hendrix SL, Howard BV, Hsia J, Hubbell FA, Johnson KC, Judd H, Kotchen JM, Kuller LH, Langer RD, Lasser NL, Limacher MC, Ludlam S, Manson JE, Margolis KL, McGowan J, Ockene JK, O'Sullivan MJ, Phillips L, Prentice RL, Sarto GE, Stefanick ML, Van Horn L, WactawskiWende J, Whitlock E, Anderson GL, Assaf AR, Barad D, Investigators W's H I (2006) Calcium plus vitamin D supplementation and the risk of fractures. N Engl J Med 354:669-683
2. Wactawski-Wende J, Kotchen JM, Anderson GL, Assaf AR, Brunner RL, O'Sullivan MJ, Margolis KL, Ockene JK, Phillips L, Pottern L, Prentice RL, Robbins J, Rohan TE, Sarto GE, Sharma S, Stefanick ML, Van Horn L, Wallace RB, Whitlock E, Bassford T, Beresford SA, Black HR, Bonds DE, Brzyski RG, Caan B, Chlebowski RT, Cochrane B, Garland C, Gass M, Hays J, Heiss G, Hendrix SL, Howard BV, Hsia J, Hubbell FA, Jackson RD, Johnson KC, Judd H, Kooperberg CL, Kuller LH, LaCroix AZ, Lane DS, Langer RD, Lasser NL, Lewis CE, Limacher MC, Manson JE, Investigators W's H I (2006) Calcium plus vitamin D supplementation and the risk of colorectal cancer. N Engl J Med 354:684-696

3. Chlebowski RT, Johnson KC, Kooperberg C, Pettinger M, Wactawski-Wende J, Rohan T, Rossouw J, Lane D, O'Sullivan MJ, Yasmeen S, Hiatt RA, Shikany JM, Vitolins M, Khandekar J, Hubbell FA, Investigators W's H I (2008) Calcium and vitamin D supplementation and the risk of breast cancer. J Natl Cancer Inst 100:1581-1591

4. Brunner RL, Wactawski-Wende J, Caan BJ, Cochrane BB, Chlebowski RT, Gass ML, Jacobs ET, LaCroix AZ, Lane D, Larson J, Margolis KL, Millen AE, Sarto GE, Vitolins MZ, Wallace RB (2011) The effect of calcium plus vitamin D on risk for invasive cancer: results of the Women's Health Initiative (WHI) calcium plus vitamin D randomized clinical trial. Nutr Cancer 63:827-841

5. Hsia J, Heiss G, Ren H, Allison M, Dolan NC, Greenland P, Heckbert SR, Johnson KC, Manson JE, Sidney S, Trevisan M, for the Women's Health Initiative Investigators (2007) Calcium/ vitamin D supplementation and cardiovascular disease in women. Circulation 115:846-854

6. LaCroix AZ, Kotchen J, Anderson G, Brzyski R, Cauley JA, Cummings SR, Gass M, Johnson KC, Ko M, Larson J, Manson JE, Stefanick ML, Wactawski-Wende J (2009) Calcium plus vitamin D supplementation and mortality in postmenopausal women: the Women's Health Initiative calcium-vitamin D randomized controlled trial. J Gerontol A Biol Sci Med Sci 64:559-567

7. Wallace RB, Wactawski-Wende J, O'Sullivan MJ, Larson JC, Cochrane B, Gass M, Masaki K (2011) Urinary tract stone occurrence in the Women's Health Initiative randomized controlled trial of calcium and vitamin D supplements. Am J Clin Nutr 94:270-277

8. Bolland MJ, Grey A, Avenell A, Gamble GD, Reid IR (2011) Calcium supplements with or without vitamin D and risk of cardiovascular events: reanalysis of the Women's Health Initiative limited dataset and meta-analysis. BMJ 342:d2040. doi:10.1136/bmj.d2040

9. Bolland MJ, Grey A, Gamble GD, Reid IR (2011) Calcium and vitamin D supplements and health outcomes: a reanalysis of the Women's Health Initiative (WHI) limited-access dataset. Am J Clin Nutr 94:1144-1149

10. Chlebowski RT, Pettinger M, Kooperberg C (2011) Caution in reinterpreting the Women's Health Initiative (WHI) calcium and vitamin D trial breast cancer results. Am J Clin Nutr. doi:3945/ ajcn.111.027664

11. Iso H, Stampfer MJ, Manson JE, Rexrode K, Hennekens CH, Colditz GA, Speizer FE, Willett WC (1999) Prospective study of calcium, potassium and magnesium intake and risk of stroke in women. Stroke 30:1772-1779

12. Bostick RM, Kushi LH, Wu Y, Meyer KA, Sellers TA, Folsom AR (1999) Relation of calcium, vitamin D and dairy food intake to ischemic heart disease mortality among postmenopausal women. Am J Epidemiol 149:151-161

13. Al-Delaimy WK, Rimm E, Willett WC, Stampfer MJ, Hu FB (2003) A prospective study of calcium intake from diet and supplements and risk of ishemic heart disease among men. Am J Clin Nutr 77:814-818

14. Ascherio A, Rimm EB, Hernán MA, Giovannucci EL, Kawachi I, Stampfer MJ, Willett WC (1998) Intake of potassium, magnesium, calcium and fiber and risk of stroke among US men. Circulation 98:1198-1204 
15. Kuanrong L, Kaaks R, Linseisen J, Rohrmann S (2011) Associations of dietary calcium intake and calcium supplementation with myocardial infarction and stroke risk and overall cardiovascular mortality in the Heidelberg cohort of the European Prospective Investigation into Cancer and Nutrition study (EPIC-Heidelberg). Heart 98:920-925

16. Neuhouser ML (2003) Dietary supplement use by American women: challenges in assessing patterns of use, motives and costs. J Nutr 133:1992S-1996S

17. Neuhouser ML, Patterson RE, Levy L (1999) Motivations for using vitamin and mineral supplements. J Am Diet Assoc 99:851-854

18. Prentice RL, Langer R, Stefanick M, Howard B, Pettinger M, Anderson G, Barad D, Curb D, Kotchen J, Kuller L, Limacher M, Wactawski-Wende J, for the Women's Health Initiative Investigators (2005) Combined postmenopausal hormone therapy and cardiovascular disease: toward resolving the discrepancy between Women's Health Initiative Clinical Trial and Observational Study Results. Am J Epidemiol 162:404-414

19. Prentice RL, Langer R, Stefanick ML, Howard BV, Pettinger M, Anderson G, Barad D, Curb JD, Kotchen J, Kuller L, Limacher M, Wactawski-Wende J, for the Women's Health Initiative Investigators (2006) Combined analysis of Women's Health Initiative observational and clinical trial data on postmenopausal hormone treatment and cardiovascular disease. Am J Epidemiol 163:589-599

20. Prentice RL, Chlebowski RT, Stefanick ML, Manson JE, Langer RD, Pettinger M, Hendrix SL, Hubbell FA, Kooperberg C, Kuller LH, Lane DS, McTiernan A, O'Sullivan MJ, Rossouw JE, Anderson GL (2008) Conjugated equine estrogens and breast cancer risk in the Women's Health Initiative clinical trial and observational study. Am J Epidemiol 167:1407-1415

21. Prentice RL, Chlebowski RT, Stefanick ML, Manson JE, Pettinger M, Hendrix SL, Hubbell FA, Kooperberg C, Kuller LH, Lane DS, McTiernan A, O’Sullivan MJ, Rossouw JE, Anderson GL (2008) Estrogen plus progestin therapy and breast cancer in recently postmenopausal women. Am J Epidemiol 167:1207-1216

22. Prentice RL, Pettinger M, Beresford SA, Wactawski-Wende J, Hubbell FA, Stefanick ML, Chlebowski RT (2009) Colorectal cancer in relation to postmenopausal estrogen and estrogen plus progestin in the Women's Health Initiative clinical trial and observational study. Cancer Epidemiol Biomarkers Prev 18:1531-1537

23. Prentice RL, Manson JE, Langer RD, Anderson GL, Pettinger M, Jackson RD, Johnson KC, Kuller LH, Lane DS, Wactawski-Wende J, Brzyski R, Allison M, Ockene J, Sarto G, Rossouw JE (2009) Benefits and risks of postmenopausal hormone therapy when it is initiated soon after menopause. Am J Epidemiol 170:12-23

24. Women's Health Initiative Study Group (1998) Design of the Women's Health Initiative Clinical Trial and Observational Study. Control Clin Trials 19:61-109

25. Jackson RD, LaCroix AZ, Cauley JA, McGowan J (2003) The Women's Health Initiative calcium-vitamin D trial: overview and baseline characteristics of participants. Ann Epidemiol 13:S98S106

26. Langer RD, White E, Lewis CE, Kotchen JM, Hendrix SL, Trevisan M (2003) The Women's Health Initiative Observational Study: baseline characteristics of participants and reliability of baseline measures. Ann Epidemiol 13:S107-S121

27. Curb JD, McTiernan A, Heckbert SR, Kooperberg C, Stanford J, Nevitt M, Johnson KC, Proulx-Burns L, Pastore L, Criqui M, Daugherty S, Morbidity WHI, Committee M (2003) Outcomes ascertainment and adjudication methods in the Women's Health Initiative. Ann Epidemiol 13:S122-S128

28. Patterson RE, Levy L, Tinker LF, Kristal AR (1999) Evaluation of a simplified vitamin supplement inventory developed for the Women's Health Initiative. Public Health Nutr 2:273-276

29. Patterson RE, Kristal AR, Levy L, McLerran D, White E (1998) Validity of methods used to assess vitamin and mineral supplement use. Am J Epidemiol 148:643-649

30. Patterson RE, Kristal AR, Tinker LF, Carter RA, Bolton MP, Agurs-Collins T (1999) Measurement characteristics of the Women's Health Initiative food frequency questionnaire. Ann Epidemiol 9:178-187

31. Manson JE, Allison MA, Carr JJ, Langer RD, Cochrane BB, Hendrix SL, Hsia J, Hunt JR, Lewis CE, Margolis KL, Robinson JG, Rodabough RJ, Thomas AM (2010) Calcium/vitamin D supplementation and coronary artery calcification. Menopause 17:683-691 